\title{
The Impact of Cross-Cultural Differences on Project Performance: A Study of Power Sector Development Operation and Electricity Sector Development Project in Uganda
}

\author{
Gubala Fredrick ${ }^{1} \&$ Olawumi D. Awolusi ${ }^{2}$ \\ ${ }_{1}^{1}$ University of Roehampton, London, UK \\ ${ }^{2}$ Kampala International University, Kampala, Uganda \\ fredrick.gubala@roehampton-online.ac.uk, awolusi.olawumi@kiu.ac.ug
}

\begin{abstract}
The purpose of this research was to establish a relationship between people's cultural attributes, multinational project management processes, project technologies and project performance in Uganda's energy sector concerning the practice during the implementation of the Power Sector Development Operation (PSDO) and Electricity Sector Development Project (ESDP) as case studies. The study employed a comprehensive survey design which mostly quantitative thus requiring the collection and analysis of data. It tangled both analytical and descriptive research designs. The research targeted 136 project beneficiaries or 'project clients' spread across the various target areas. The simple random sampling method was employed. Data compiled was reviewed to fill any gaps for incompleteness and inconsistency. This was to make ensure the exactness of the material provided acquired from the participants, through the continued reviews and comments provided by the Supervisor. Data was re-organized and software called the Statistical package. For social scientists (SPSS) was used to enter the data and analyze it, the results indicated a strong positive correlation people's cultural attributes and project performance, multinational project management processes and project performance and between project technologies and project performance $\left(\mathrm{r}=.535^{* *} \mathrm{p} \leq\right.$ $0.01, r=.758^{* *} \mathrm{p} \leq 0.01$ and $\mathrm{r}=.656^{* *} \mathrm{p} \leq 0.01$ ) correspondingly. It was concluded that people's culture attributes, multinational project management and project technologies are pre-requisites for effective project performance in the Power Sector Development Operation Project and Electricity Sector Development project in Uganda and that Project technologies are a better predictor of project performance. The suggestion or recommendation for project managers to ensure that they progress implementation of their projects, peoples culture attributes, multinational project management and project technologies need to be enhanced through training of project staff and effective involvement of the communities.
\end{abstract}

Keywords: Cross-cultural differences; Project performance; Multinational project management processes; Project technologies; Uganda.

\section{Introduction}

As the global economy continues to grow and multi-cultural/national projects become the norm across borders, it's very critical for all project managers/practitioners to be curious of the impact cultural diversity has on project performance and excellence. Project managers and beneficiaries ought to be aware of the cultural differences while at the same time focusing on attaining project goals and deliverables. Culture according to Hansen et al, (2003), corroborated by Hofstede (1997), has diverse definitions, Hansen defines culture as the decrees and duties shared by people of a specific society. Development projects in developing countries often leverage talents from a diversity of backgrounds and nations; this according to Steers, et al (2013), his recipe for misunderstandings and conflicts on projects. It has been argued that cross-cultural project teams can offer critical elements.

For active project performance (Ying et al., 2015), this is not to undermine other project performance indicators like schedules and budget performance among others. This research was, however, limited to the influence of cross-culture differences on the performance of projects. It has for instance been urged that individuals coming from different national and organizational cultures, which are enhanced by dissimilar involvements and organizational theories, through combinations of services would perceive project goals differently (Ching et al., 2014). Hofstede's (2011) study also describes culture as "the shared programming of the observance that extricates the associates of a unique group or grouping of individuals from others". However, the author's publication coins a more distinctive definition relevant. 
To this study as "the collective ways of acting, thinking, and feeling," Lima and Patah (2016), assert that the understanding of the effect of the influences of culture is vital in the execution of, global projects. PMI, (2013), also highlights that the need for multicultural competence becomes a critical factor for effective project managers this therefore calls for project performance practitioners to appreciate that diversity in culture has considerable capacity to influence project performance either negatively or positively. Culture is such a strong mitigating factor of project performance (Ying et al., 2015). Their observations about the role of culture in project-based environments guided the conceptualization of this research basing on three fundamentals of project management, which are; the People, technological Knowledge and Procedure as those involved in influencing project performance, mitigated by culture. The Power Sector Development Operation Project was a Government of Uganda Project with co-funding from the World Bank of the International Development Association (IDA) whose objective was reducing the medium-term electricity shortages, imbalances in the energy finances, and facilitates an orderly strategic span expansion of electricity services. This project had a set of investment and policy procedures intended to decrease the demand gap of the supply until the oncoming of the Hydropower plant at Bujagali and also offer financial support to Government by absorbing the high tariffs of the thermal power provided in the short term (worldbank.org, 2018). The project involved the establishment of $137 \mathrm{kms}$ of $220 \mathrm{kV}$ Kawanda to Masaka power transmission line and the construction of the associated substations.

In addition to the resettlement the affected persons among other activities (worldbank.org, 2018). These projects were all implemented by the Ministry of Energy and Mineral Development (MEMD) in support, with other energy sector agencies. They were true cases-studies of understudying cross-cultural differences in project implementation at all phases. This was drawn from the stakeholders involved, for example, the Electricity Sector development project whose stakeholders comprised of the National Environment Management Authority (NEMA), the Uganda Electricity Transmission Company Ltd (UETCL), UMEME Ltd, the Local District Councils of Wakiso, Mpigi and Masaka, Kampala Capital City Authority, National Forestry Authority, Wetland Division of Ministry of Water and Energy, World Bank and the general public. The study assumed that all these stakeholders present cross cultures (institutional, communication protocols, socioeconomic structures etc.) that have a bearing on the project implementation. However, Uganda, being an emerging economy, with several projects both ongoing and other in the pipeline, has countless of challenges related to project management both practical and non-practical which have affected the success of Internationally Funded projects (Auditor General's report 2015). Firstly, experimental papers/studies are scarce on the excellence or otherwise of projects implemented in Uganda, which has left no documents detailing the lessons learnt and or the best practices in this field. Also, though projects in overall have their trials concerning application and subsequently success, specific infrastructural projects are overwhelmed with several issues and challenges (Mansfield et al, 2015). For example, the very nature of cross-culture attributes on multi-stakeholder projects.

In Uganda postures a momentous challenge that befalls both National and Private Agencies. The government acquired the loan from the World Bank to implement the ESDP in 2011 and USD.300 Million, for implementing the Power Sector Development Operation Project as well. The general objectives were to decrease the effect of the medium-term electricity shortages and manage the imbalances in the electricity financial and enable a well-organized strategic expansion of the electricity sector as well as also enhance the access of bulk power in the Country's Southwest region (World Bank group 2018). The Projects were to run through 2017, however, by 2015 , only $10 \%$ of the money had been claimed as a result of absorption challenges. At the time of the mid-term review, only $10.83 \%$ was absorbed, this was out of the entire portfolio under ESDP. That underutilization of funds that resulted from low project disbursements negatively affected project progress, this led to Government incurring needless expenses in loan commitment fees for the outstanding balances during the period, these issues were largely related to the lengthy procurements fueled by cross-cultural differences and technology differences between the donor and the local implementing agencies (Auditor General's report 2018). The project work plan review also revealed that the execution of various project activities had greatly delayed. Specifically, the implementation of lighting systems in the selected streets and Markets in Masaka Municipality, the study to understudy the power sector reforms in Uganda and the installation of a power sector information Centre, this portrayed that donor interests often put a spanner in the controls subsequent in postponements in the application. 
Changes in scope, and occasionally a consequent cancellation of a project (Meng, 2011). These and many other issues in the management of projects have influenced the general quality and success of projects in Uganda. Also, an evaluation at the energy efficiency logistics supplied under the PSDO was hardly seen, implying that the project supplies did not survive enough to create an impact among the beneficiary communities, raising questions as to where this was the need of the beneficiaries at the time (Jetu, Riedl and Roithmayr, 2010). A cross-examination of the reasons was attributed to cross-cultural challenges owing to the cultural differences between the project stakeholders. Considering the countless problems that are facing project managers in Uganda, the purpose of the research was to assess and identify the nature of people's cultural attributes, multinational project management processes, and project technologies and rank the elements that affect project performance. Information on the appropriate practices would greatly improve the match of people's cultural attributes, meet the multinational project management processes as well as project technologies and in turn the much-needed success of the project. This research adds to the information on people's cultural attributes, multinational project management processes, project technologies and project performance.

Consequently, the main aim of the present study was to investigate the relationships between cross-cultural aspects in development projects specifically financed by the International Development Association (IDA) and project implementation in Uganda using the Power Sector Development Operation Project and Electricity Sector Development project in Uganda as case studies. However, the specific objectives are as follows:

- Evaluate the relationship between people's cultural attributes and project performance

- Evaluate the relationship between multinational project management processes and the performance of projects in Uganda.

- Evaluate the relationship between project technologies and project performance.

Furthermore, based on the above specific objectives, the following research questions were construed:

- What is the relationship between people's cultural attributes and project performance?

- What is the relationship between multinational project management processes and the performance of projects in Uganda?

- What is the correlation between project technologies and project performance?

The research focused on people's cultural attributes, multinational project management processes, project technologies and project performance in Uganda. The research was conducted on various projects in the Power Sector Development Operation Project and Electricity Sector Development project in Uganda as case studies. The study aimed at helping policymakers in focusing, identifying and developing a more favorable policy environment to increase project performance in Uganda. The study acts as a platform for developing, clarifying, understanding, and facilitating cross-cultural differences in project performance. The material resulting from this research could be used to inform the organizing, planning, guiding and monitoring specific policies that would improve the success of projects in Uganda. Lastly, the research will enhance knowledge of the current literature aimed at the benefit of upcoming examiners and academicians that would be interested in this knowledge area.

\section{Review of Related Literature}

Conceptual Review: A project has been explained by several scholars in dissimilar ways. This study considered Ofori (2013) reported definition by Wysocki, Beck and Crane (2000), as an arrangement of exclusive, complicated and related pieces of works aiming at a common goal or resolve that should be executed within a specific period while using controlled resources at a certain desired qualities. Ofori (2013) also agreed with Meredith and Matel, (2000) who posit that projects are categorized using general characteristics e.g. its purpose, period, exclusivity, interrelations and conflicts. To break down the meaning of project performance, Bojesson (2015) underscores project effectiveness and efficiency as practices that are ordinate towards a goal that is aimed at delivering success. Within Power Sector Development Operation Project and Electricity Sector Development project in Uganda as case studies. According to Turner and Muller (2005), the efficiency considers maximizing production for a specified level of contribution whereas Ojanen 
et al (2002) attribute effectiveness as the grade for which a programmed objective is reached, the grade at which the definite product matches.

The intended product (O'Donnell and Duffy, 2002), or as the degree at which client requirements are obtained (Neely et al., 1994). On the other hand, efficiency can be known as doing things correctly, while effectiveness as doing the correct things. These definitions rhyme with Crawford \& Cox (2007) assertion that to be successful, the performance of infrastructural projects should mostly rely on effectiveness and efficiency in the activities undertaken. He added that infrastructural projects regularly have a planned value once a clean assembly is made between how knowledgeably and efficiently projects are performed in addition to in what way the outputs and services deliver value to the interested stakeholders. It has been urged that planning is a strong component of project performance. While dismissing ad-hoc planning in project delivery, Ofori (2013), said that part-time preparation might lead to non-achievement of the time value of projects and may result into cost increase, which in turn affects project quality. Consequently, coming out clearly on the scope of the project and the desired specifications at the inception phase enables the project funders/donors and the management team to spell out the purpose of the project, its intended outcomes, the necessary required resources and the required period of execution. His argument implied indeed project success substantially relies on the completeness of the planning stage hence its criticality. It has also been argued that in numerous circumstances, the project scope is affected since the loss in implementation time sometimes presents pressures that result in demands that require changing the scope from the original.

Ofori (2013) advises that planning for the project should be an inclusive process that involves all project stakeholders to capture all their needs/interests and to ensure harmonization on the project scope and other key requirements. He further guided that in cases of infrastructural projects which include huge investments with long implementation periods; their planning phase should embed a lot of monitoring of the process and ensuring all aspects of the execution process are well controlled. Demonstrating that effective monitoring and continuous evolution of the project process improves the accomplishment rate of the project. Literature has also highlighted critical project success factors as key development project performance indicators. Frese and Sauter (2003), corroborated by Project Management Institute - PMI (2013), agreed that these serious success issues involve a set of project influencers which are powerfully linked to the success of the project. Their growth or mitigation, are depending on whether they are favorable or negative, which will determine the project performance. These key achievement factors are the few areas where if outcomes are not satisfactory, the organization's exertions for the phase will not be desired. These have been listed to include; Decent Preparation, Strong Concern and Responsibility, plus the Plan Regulator in addition to the leadership of the Project and Governance, and relations in communications are key areas of successful projects. Hence, it can be argued that development projects with a well-pronounced project plan, a plan with a clear risk analysis, and input from shareholders will most likely be judged as having performed well.

\section{Figure 1: Conceptualization of Impact of Cross Culture on Project Performance}

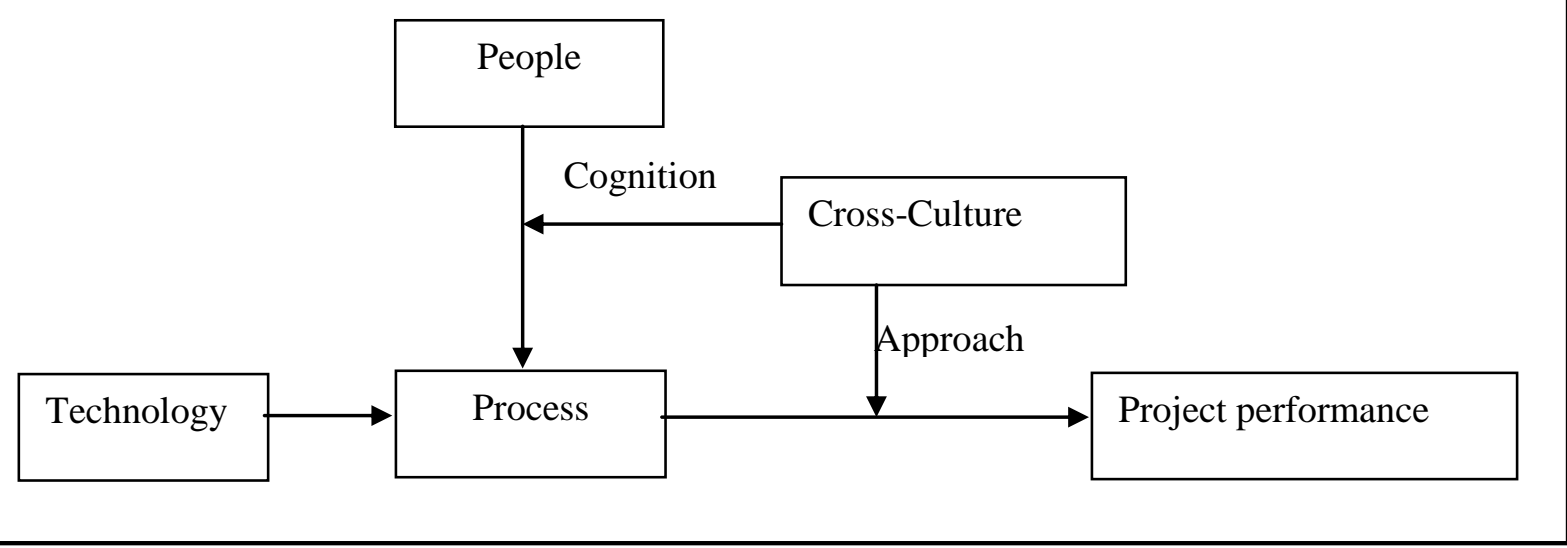

Source: Literature (Beardwell and Holdens (2001), and Kuen (2007) 
From figure 1 above, Ying et al. (2015) posit that among the vital variables that influence project performance is culture, based on approaches appreciated by the different project participants. They also indicated that participants (people)'s perceptions depending on their cognitive capacities influenced their appreciation of the processes in project implementation. In the same reasoning, technology was depicted as having a strong influence on project processes and that it also impacted project performance. Their model was enlightened in such a way that projects carried out by persons coming from various national cultures, the technical skill which implies the target/instrument/content/ of the project perform very small influence on the ultimate project performance and process, due to its passive nature in the process of the project. They also indicated that people were more critical in influencing the project process just like they noted that culture in its completeness (irrespective of national culture, individual culture or organizational culture) showed variances in impacting on people's cognitive capacity in gripping data, problem-solving, calculating, and making decisions. And further, diverse procedures are understood by persons with diverse national cultures, who ultimately present varying project performances. For this study people's cultural attributes was an independent variable as cited in Ying et al. (2015), While Multinational project management processes was another independent variable as cited in Todorović et al. (2015), and Cheng et al., (2010), Project technologies was the last independent variable as cited by Ahimbisibwe \& Nangoli (2012).

Figure 2: Conceptual Framework

\section{People's cultural attributes}

\section{Project technologies}

\section{Multinational project management processes}

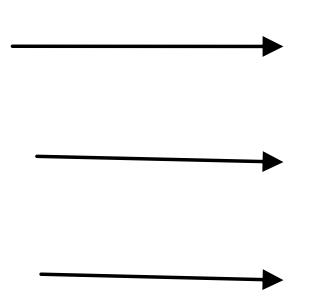

Source: Review of literature

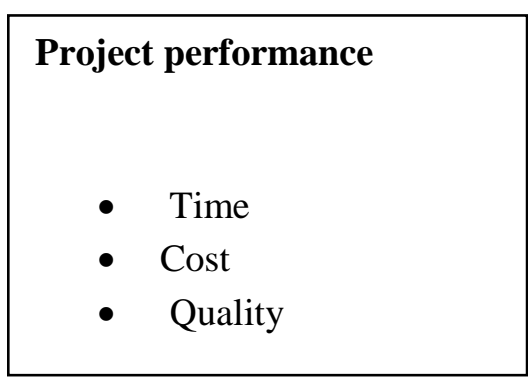

The Resource-Based View Theory: Campbell (2004) suggests that competitive advantages can be used to expound on the knowledge surrounding the resource-based. He further explains that it the theory opposes that competitive advantages are embedded in the organization's numerous resources, saying that any organization can be exposed and also utilizes and not in the capability to realize the situation. The theory conserves that formations are well gifted with numerous resources in the form of resources, assets, capabilities, procedures, and alternatives that give the organization a competitive advantage in the market. Since companies have dissimilar aspects at the various levels and different bundles of resources, variances in organizational concert are likely to be observed (Daniel \& Reitsperger, 1991). The theory further asserts that firms have three types of assets that include; physical resources, immaterial resources and organizational abilities. Physical resources include the finances, physical, high-tech and administrative resources and they are easily recognized, while immaterial resources are not easily identified as they are more complex and therefore hard to reproduce.

They include key plans that a firm implements over some time and climaxes to better performance (Barney \& Clark, 2006). Finally, organizational competencies are skills and capabilities that a firm combines to transform physical and immaterial resources into productivities, for example, outstanding customer service (Sink, 1985). The resource-based theory contends that organizational assets are not in themselves a basis for competitive advantage because competing companies might likewise own alike assets. Therefore, competitive advantage is embedded in the assets owning one or more of other features such as cherished alternatives. Thus a firm can only maintain a competitive advantage only if other companies are unable to replicate similar features (Sink, 1985). The theory argues that a firm needs to harness its resources using organizational repeatable knowledge that ensures it a competitive advantage. Skinner (1969) posits that achieving and developing organizational competence is paramount to achieving competitive advantage and therefore competitive advantage is obtained from the organization's capability. 


\section{Empirical Reviews}

Project Technologies and Project Performance: Innovation in the way business is conducted is an aspect of technology that Bojesson (2015), poses and an alternative way to improving the hitherto narrow of improving the performance in organizations. This is premised on the assertion that innovation improves the efficiency of the projects. He argued that persistence of the "The industrial problem" suggests that creativities do not usually aim at the right areas implying that they most likely find problems in discovering solutions that may result in improved performance. Therefore, there should be requirements for improved creative/innovative thinking relating on how to prepare for projects in addition to the needs to increased comprehension of how the impact of the different situation on the performance of the project. This will enable innovative solutions to emerge. Clarkson and Eckert (2010) indicate that as result of the advancement of technologies coupled with intense struggles for the global market share among companies, organizations are compelled to be more innovative and continually create products that are better and efficient. Development projects ought to adopt this approach of designing better, faster and more efficiently.

This is likely to have a direct impact on the reduction in delivery time. Thus, saving money and ensuring time value these projects that often suffer from extensions. In arguing for technological capability as an organizational resource capable of enhancing project performance and success, it should be worth noting that both these capabilities have far likely chances of producing more value for any organization as indicated by Helfat et al. (2007). To appreciate and employ the knowledge instead of simply having the resources available. The theory further argues that competitiveness should be maintained by a culture which inspires fair distribution and swapping capacities, abilities and abilities done through organizational learning. They comprise an intricate mix of knowledge, skills, routines, technologies and values Battistuzzo and Piscopo (2015). The efficiency of any organization in developing capabilities which include those required in executing valuable projects is indeed a key determiner in the likeliness of having a good performance of these projects. This capacity is what is called a dynamic capability which mostly survives on the ability to innovate new capacities.

Crawford \& Cox (2007) states that it is indeed high effectiveness levels and efficiency of the process involved that guarantee the success of the development process of a product. It is quite important to appreciate the characteristics of the specific project since it guides in the linking of the project's implementation to the economic value of the organizations. It is with no doubt that the characteristics of the project are critical to ensure effective management of the project, however, engaging new technologies will stand better chances to deliver more efficiently and effectively and therefore perform better. Some practitioners observed huge companies have increasingly employed complicated models; this has especially been in the last two decades, to improve their process management of sophisticated projects. However, this desire to improve the efficiency of projects, through increased monitoring and control in these projects has not yielded results as expected, in most cases (Marmgren and Ragnarsson, 2014). They Implied that the transformations in technology should match other key elements of production like human resource, this mitigates the risks of improvements in the procedure and abilities being incapacitated by un-matching competences of other production factors.

People's Cultural Attributes and Project Performance: Earlier studies posited that culture, be it organizational or national culture impacts to project performance. Without disagreement Turner (2009) Wiewiora (2013) and Ching et al. (2014) uphold the significance of cross cultures in project performance and success. Turner (2009) recounts the Hofstede dimensions to the different phases of the project's life cycle which to him characteristically are constituted by; the feasibility - survey whether a project is a sensible undertaking worth implementing. Feasibility studies approaches reflect cross-cultural dimensions and the decisions and reported has a lot to do with cultural dimensions of the teams involved. Design - concocting a detailed plan of activities, which include costing, the risk appraisal and the quality among others, also reflects cultures and impacts of project performance. Implementation - the real accomplishment of the plan. A lot of what happens at this stage is a reflection of the cultural dimensions of the teams. Closing-out - completion of the entire project. All the phases require independent skills sets and abilities that are strongly espoused. 
Influenced by the organization or national cultures of the teams involved. Turner (2009) exemplifies this by saying that whereas innovativeness is valuable encouraged at the conceptual phase, it may not be as important during the implementation phase where procedures are followed step by step as per plan. Zeng et al. (2013) and Obikunle (2002) argued that a set of traits of a certain group of people and how they perceive communication or align towards the society can be used to categorize culture. Majority of the development projects require that different people across nationalities, education levels, administrative roles and interests constitute teams to work as one. This calls for addressing culture differences to galvanize around common interests. People have to adapt themselves to the reality of the teams in which they will work. The culture of that development project team to focus during the development of their significance in society and regulations enables them to get further identify themselves or lose the grid and weaken. This is in the end reflected in how the project performs. Pires and Macedo (2006) have argued that it is a culture that reproduces the beliefs and morals that the group and its members share. These beliefs are articulated through codes, which include rituals, myths, legends, stories, and a specific language, which influences how members that belong to a certain culture to contemplate and make verdicts. They will thus bear collective responsibility for success or failures on the project.

Referring to the important work carried out by Hofstede (1997), who stressed that national culture has a strong impact on employees (ITAP International, 2014) when he elaborated that evidence illustrates that the national cultural beliefs are adopted much earlier, held profoundly, and slowly change over the different generations. They have a strong impact on people that they are reflected on cross-culturally implemented projected (Ofori (2013). Another dimension of culture in project performance is Organizational Culture: This is the conduct of persons that belong to an organization and the connotations that these persons ascribe to their activities. This culture comprises the organization beliefs, systems working language, visions, norms, habits, symbols ITAP International (2014). Organizational culture influences several scopes of the work setting and, therefore, the main strength of the course of business. How the work packages are accomplished is reflected and the objectives are attained. The persons are focused on the attainment of objectives. Culture guides the decision-making process, the comprehension, feeling and responding to the threats and the opportunities. It is entrenched in the people and often influences their perceptions and thus affects their presentation. Culture may hurt project performance or success where management of leadership does not have adequate knowledge about the diverse cultures of the team members of that they lead or that of the beneficiaries.

Cultures may result into difficulties in relationships, misinterpretations, conflicts, communication, tensions, lack of self-assurance, and mismatches about customs, beliefs, language, values and religion particularly in teams that are distant in geographical locations that are sustained through remote contact. All of these issues stated agree with the account of Lin et al. (2012), who quantified that there may be difficulties in multiethnic relations related to work stemming from communication gaps, language barriers, political disagreements and religious affiliations which are all largely due to the diversity in the cultures. Culture controls to a significant amount of the way groups of people and companies function daily, the numerous difficulties that organizations face more often are a result of wrangles produced by cultural differences (Wheelwright, 2010). Hence, the assortment naturally observed amongst employees of any corporation necessitates keen management attention especially in case of differences to ensure that interrelations among these employees are driven by sensitivity and capabilities to ensure that leaders have a close amicable relationship with the subordinates (Russo, Ruiz and Cunha, 2005). Short of that, is a recipe for project performance being undermined by unwarranted rifts driven by underlying cross-cultural, differences. Therefore tandem with Lima and Patah (2016), among the required capabilities from a project manager, is their capability to comprehend the culture of the team members or the project staff. Lack of this awareness brings problems for the management due to the most varied types of misunderstanding.

Multinational Project Management Processes and Project Performance: Todorović et al. (2015) affirm that, over recent decades, projects have been increasingly utilized as a meant to attain business goals. Notwithstanding that, different researchers have given utmost consideration to how project management is practiced and the success of projects, the performance of the different projects in various countries has continued to dissatisfy stakeholders (Gleitsmann, 2005). Irrespective of whether the business is based on 
projects or operations, the performance of projects directly translates into highly needed results and in that way, it has a straight bearing on the overall organizational performance. It is then in the interest of any countries to recognize the elements that enable and strengthen International project management processes (Chiang, 2009). According to Cheng et al., (2010), project management processes involve guiding and organizing both human and assets resources during the life cycle of a project by using contemporary techniques in management to attain desired goals within the required scope, cost, time, quality and stakeholder gratification or performance.

However multinational project management processes can are observed as a section part of general management besides the main engineering, construction, health and safety, manufacturing, Military among other sectors (Badiru, 2008). International projects are sponsored through credits or absolute grants, and the capital agency/body in most cases lead the identification of the sector project and its policies are found to supersede those of the borrower country and it also the determination of their project objectives (Chiang, 2013). These projects normally take up to three to five years, through the funding window can go even up to a decade (Cheetham \& Chivers, 2005). Internationally funded projects are identified, planned, and executed in an explicit framework (Cheetham \& Chivers, 2015). Below the dominant program method, these projects would be part of a development agenda and are well aligned to the national visions and strategic objectives (European Commission, 2007). However, Multinational project management processes necessitate three discrete significant stakeholders: the donor agencies, which provide the capital to develop the investments; the units that implement the project, these are involved in the designing and implementation of the project; lastly, the ultimate beneficiaries of the project deliverables who utilize the investments to uplift their socialeconomic wellbeing (Khang and Moe, 2008).

Those unswervingly exaggerated; those indirectly exaggerated; National Government and the private sector departments; and the donor's agency, consultants. However, according to Hallowell and Toole (2009), a strong economic burden has advanced in the implementation of multinational projects during the last decade; this has led to failure to complete projects in agreed timelines caused by high levels of the country's external debts. This has opened up a strong debate on how projects are developed, prioritized and financed, especially the high investment projects like roads, railways etc. This story is similar to all corners of the African continent. When a project manager delivers the specified quality of project deliverables with the utilization of the availed resources within the specified schedule, the project is rated (Harrell \& Bond, 2006). This achievement is owned to the ability of the project managed practitioner to ensure effective coordination of project activities to make sure all resources are optimally utilized, project assignments are executed as per the schedule and within the time provided (Schmid and Adams, 2008). In addition to meeting all stakeholder interests and expectations (Project Management Institute, 2008). The project manager is obligated to show the mandatory leadership skills which are vital for the execution of a successful project, in addition to having the capacities to lead the entire team through the entire project cycle (Sumner, et al, 2006).

The project manager's skill to effectively lead a team and meet the goals is essential to the success of a project (Hyvari, 2006). It is a comparatively contemporary preparation that efforts to reach thoughtful resolves within the explicit time and cost limitations, using ideal use of resources and through using a joint groundwork and controller system. The development and reception of project management techniques are continuing to rise as resources become scarce in less developed countries. The competence of the public sector is essential to the development of the economy (Ahimbisibwe \& Nangoli, 2012). The requirement for project management knowledge in the public sector organizations has become important to deal with the huge accountability of supervising various projects. Earlier researchers have observed the gap for a continuous life cycle based involvement of stakeholders in design, construction and engineering projects as lack of or inadequate stakeholder involvement has been substantially accountable for the numerous project failures. More gaps observed from the literature review include the following: Significant phases in people's cultural attributes include cultural conservation, culture identity and community livelihoods with community involvement.

The identification of people's cultural attributes is directed by the definition of culture though there should be a need to cast out a description which combines both the extensive and brief definitions identified in the 
existing literature on people's cultural attributes. Furthermore, various international project management processes were recognized with the necessity to advance a profound understanding of how their relationship and should be employed to improve project performance mainly emphasizing infrastructural projects as well as their relation to the success of the project. Stakeholders cultural attributes and their corresponding interests in projects are observed to be active hence there is need appreciate why people's culture attributes or welfares change and track same during the execution of projects. The existing framework used for project technologies in infrastructural projects does not discourse the need for a life cycle based project technologies framework. There is a need for the obligation of responsibility for leading the people's cultural attributes processes, understanding the effect of the multinational project management processes on project success in infrastructural projects. It is required to further appreciate the application of project management techniques and the various toolsets.

\section{Methodology}

The section covers the framework that directed the implementation of the research, that is; the research design, the research target population/communities and the sample size, the sampling approach and adopted procedure, response rate, data collection, measurement of variables, Reliability of the Instrument and Data Processing, Presentation and Analysis.

Research Design: Kothari (2004) stated that research design should be a conceptual structure that guides the implementation of the research. The study adopted a cross sectional survey design that was quantitative involving the collection of information and data analysis. This is justified that a cross-sectional survey collects data to brand extrapolations around a populace of attention at a given point in time (Lavrakas, 2008). Since the research focused on testing instead of generating theory, it implemented a quantitative analysis approach because research methods of the kind only utilize numbers and anything measurable in a methodical way of examination of occurrences and their connections (Awolusi, 2019; Akeke., Akeke, \& Awolusi, 2015). This focused on describing and drawing inferences from the findings on the relationship between, people cultural attributes, Multinational project management processes, project technologies and project performance of IDA -World Bank-funded projects in Uganda's energy sector, comprehend the culture alignment and the social well-being of the envisioned recipients. Relationship and hierarchical reversion analysis were used to observe the relationship between the variables and the degree to which the autonomous factors enlighten project performance. This is attributed to the understanding of the relationship between two or many variables deprived of knowing the functional connections.

Sampling Design and Procedure: The simple random sampling approach was used because the study involved a larger population and with this sampling technique each member of the population had an equal chance of being included in the sample. Choa, et al. (2009), designates that the broad parts must comprise a recognized/determinate amount of populace whose interest is similar and that can be plotted or level gathered. The method of this project was based on a positivism system, where the attention of the data gathering was measured to provide dependable and precise material concerning the project that was taken to validate the essential viewpoint of the research.

Study Populace and Sample Size: The study population comprised 220 project beneficiaries or 'project clients' spread across the various target areas, the target beneficiaries of the project were chosen because they benefited from the project and were affected directly or indirectly by the Power Sector Development Operation Project and Electricity Sector Development project in Uganda (Ministry of Energy and Mineral Development report, 2017). A sample size of 136 was used in this study. This was selected conferring to the sample size determination table by Krejci and Morgans, (1970). The scholar used simple random sampling to select contributors in the survey and this guaranteed that the sample chosen was illustrative of the population and that the sample selected was unbiased.

Data Sources and Procedure for Data Collection: The study employed both primary and secondary information. The Primary data was acquired from the targeted participants. Secondary data was gotten from World Bank reports, journals, newspapers, project documents, books and all other accessible literature that 
was pertinent for the study. More Secondary data was also acquired from documented reviews which were used to collect secondary data. Additionally, Ghauri and Gronhaug (2010) confirmed that secondary data is more dependable and delivers precise material worth considering since such data is gathered by specialists using difficult test approaches and primary data approaches are beneficial because the data collected is for definite purposes it was collected for. The scholar designed a communication of introduction in form of a letter to the respondents acknowledging that this is purely academic research. The scholar presented himself to the local government authorities of the selected communities and other institutions for data collection. A pilot survey was conducted to test the validity and reliability of data collection instruments.

Thereafter, the researcher proceeded with the collection of the data from respondents, often; a local guide was used to target the eligible beneficiaries of these projects. The completed forms were collected after being filled to avoid losing them. Since the foremost component of the research underneath this study was the conduct of the societies to the projects in emphasis. The strategy of collecting the data was reliant on a factual-survey approach (Easterby-Smith, et al, 2008), it is mainly originated on the reply of the customer or in this situation the beneficiaries of these projects. The researcher, therefore, used this material from a selected sample of persons to make certain extrapolation of the wider population. All independent variables including people's cultural attributes, multinational project management processes, project technologies and the dependent variable that is project performance of these World Bank projects in Uganda's energy sector, these were acquired depending on the material of other researchers which were adjusted to match the Ugandan context.

Validity and Reliability: Validity measures the degree to which the research instrument measures accurately what it is to measure. The study used content validity to measure the degree to which the queries on the tool and the notches from these inquiries signify all conceivable inquiries that might be queried around the content or talent (Chan and Chan, 2004). To ensure content validity, the questionnaires were tested before their final administration by use of professionals and experts to cross-check whether the instrument is adaptable. This was computed by dividing relevant questionnaires by the sum of questionnaires. In other words, a content validity index of 0.7 or more is acceptable or considered good. To guarantee consistency of the research instrument, a Cronbach Alpha test was calculated as a measure of the scale reliability to determine its consistency. According to Nunnally (1978), the reliability coefficients of 0.70 or more are considered good. These items adapted have been used by researchers over time and have been proven.

Table 1: Reliability and Validity of the Research Instrument

\begin{tabular}{lll}
\hline & Cronbach Alpha & Content Validity Index \\
\hline People's Cultural attributes - 1 & .717 & .889 \\
Multinational project management & .830 & .800 \\
processes - & .798 & .867 \\
Project technologies. - 3 & .895 & .880 \\
Project performance -4 &
\end{tabular}

Source: Primary Data

Table1 displayed that the research instrument was both useable and consistent as indicated by the content validity index and the Cronbach Alpha coefficient which were above 0.70 which are acceptable according to Nunnally (1978). To address this ethical anxiety, the study side penetrated these communities through individual public leaders since they lead the societies and had prior knowledge on who was eligible. In totaling to the questioners, agreement certificates were created in command to designate whether applicants had offered their material concerning their sensation or estimation on the project and how best they thought it was custom-made in a permitted method. These pamphlets were shared with the indigenous leaders counting the aim and purposes of the education/ study for their acquisition into the workout.

Data Collection Instrument and Analysis: The data/information collected was cautiously inspected, coded prepared, and analyzed. It was obtained from dully survey forms/questionnaires, typed into the computer 
with the use of Epidata and then analyzed with the use of the SPSS tool. Data were further sorted using crosstabulations, Pearson correlation, and regression. Cross tabulations were employed to explain sample characteristics; multiple regression scrutiny was employed to find out the predictive potential of independent variables (people's cultural attributes, multinational project management processes and project technologies) on the dependent variable (project performance) while Pearson's correlation was adopted to find out the correlation between the variables of the study. The detail of the collected data was analyzed using SPSS version 22 using interpretations removed from the review agendas crosswise the complete communities while captivating into an explanation, their cultural varieties. The study used multiples linear regression analysis. As a predictive analysis, the multiple linear regressions were used to explain the relationship between the variables.

$$
r_{s}=1-\frac{6 \Sigma d^{2}}{n\left(n^{2}-1\right)}
$$

We are concerned with whether the relationship pattern between two values of variables can be described as a straight line, which is the simplest and most commonly used form. Remember from geometry class that a line is described by the formula:

$\mathrm{Y}=a+b \mathrm{X}$ (in geometry we said $\mathrm{Y}=\mathrm{mx}+\mathrm{b}$ where $\mathrm{m}$ was slope and $\mathrm{b}$ was $\mathrm{y}$-int)

Where $\mathrm{Y}$ is the dependent variable, measured in units of the dependent variable, $\mathrm{X}$ is the independent variable, measured in units of the independent variable, and $a$ and $b$ are constants defining the nature of the relationship between the variables $\mathrm{X}$ and $\mathrm{Y}$.

The " $a$ " or Y-intercept (aka Yint) is the value of $Y$ when $\mathrm{X}=0$.

The " $b$ " is the slope of the line and is known as the regression coefficient and is the change in $Y$ associated with a one-unit change in $\mathrm{X}$. A linear regression line has an equation of the form $\boldsymbol{Y}=\boldsymbol{a}+\boldsymbol{b} \boldsymbol{X}$, where $\boldsymbol{X}$ is the explanatory variable and $\boldsymbol{Y}$ is the dependent variable. The slope of the line is $\boldsymbol{b}$, and $\boldsymbol{a}$ is the intercept (the value of $\boldsymbol{y}$ when $\boldsymbol{x}=0$ ). A structured questionnaire was used to collect data from the respondents. This instrument was chosen because it allowed a systematic collection of data about the study objectives. The questionnaire consisted of four sections. The first section aimed at establishing demographic characteristics of both the unit of analysis and unit of inquiry while the next three sections were based on the study objectives for which the responses were anchored on a five-point Likert-type rating scale, ranging from Strongly Agree $=5$; Agree $=4 ;$ Not Sure $=3$; Disagree $=2$; to Strongly Disagree $=1$.

The multiple linear regression equation is as follows:

$$
\hat{Y}=b_{0}+b_{1} X_{1}+b_{2} X_{2}+\ldots+b_{p} X_{p} \text {, }
$$

where $\hat{Y}_{\text {is }}$ the predicted or expected value of the dependent mutable, $\mathrm{X}_{1}$ through $\mathrm{X}_{\mathrm{p}}$ are $\mathrm{p}$ separate independent or forecaster variables, $b_{0}$ is the value of $Y$ when all of the independent variables ( $X_{1}$ through $X P$ ) are equal to zero, and $b_{1}$ through $b_{p}$ is the estimated regression coefficients? Each reversion constant signifies the change in Y comparative to a one-unit alteration in the individual independent variable. In the manifold regression situations, $b_{1}$, for example, is the change in $\mathrm{Y}$ relative to a one-unit change in $\mathrm{X}_{1}$, field all other independent variables continuous (i.e., when the residual independent variables are held at the similar worth or are fixed). Again, arithmetical tests can be achieved to evaluate whether each regression constant is meaningfully dissimilar from zero. Correlation analysis tools i.e. the Pearson' correlation coefficient was used to establish the relationship between people's cultural attributes, multinational project management processes, project technologies and project performance in Uganda. Multiple regression analysis was conducted to determine a variance in the dependent variable that was explained by the independent variables because there was more than one study variable affecting project performance.

\section{Results and Discussion of Findings}

This section discusses the results of the quantitative techniques of the factors that influence project performance regarding cultural attributes, multinational project management processes and project 
technologies. The results are specifically focused on the questions about the research as indicated in chapter one of this Report. The chapter is dealt with in three parts. First, a summary of results is presented with the aid of tables to depict and achieve a clear understanding of the data. Secondly, correlation statistics are presented followed by the interpretation of results. Since the study was focused on establishing a relationship between the given variables, correlation analysis which addresses the relationship between two different variables was applied. Thirdly, the Regression analysis was also carried out followed by an interpretation of results. This analysis intended to inspect how the independent variables affected the dependent ones. During this research, the project performance is described as the dependent variable whereas the cultural attributes, the multinational project management procedures and the project technologies are the predictors/independent variables.

Description of Respondents: The demographic characteristics in this study included the Gender, Stakeholder Category, Place of residence, Age Category, Marital status, maximum levels of education plus the Profession. Out of 136 questionnaires that were distributed, 124 were returned giving a $91 \%$ response rate.

\section{Table 2: Individual Characteristics of the Respondents}

\begin{tabular}{|c|c|c|c|}
\hline & Gender & Frequency & Per cent \\
\hline \multirow[t]{6}{*}{ Valid } & Male & 88 & 71 \\
\hline & Female & 36 & 29 \\
\hline & Total & 124 & 100 \\
\hline & Stakeholders & & \\
\hline & Beneficiary (community member) & 79 & 63.7 \\
\hline & Management & 26 & 20.9 \\
\hline \multirow[t]{3}{*}{ Valid } & Others (specify) & 19 & 15.3 \\
\hline & Total & 124 & 100.0 \\
\hline & Place of Residence & & \\
\hline \multirow[t]{8}{*}{ Valid } & Wakiso & 10 & 8.0 \\
\hline & Kalungu & 11 & 8.8 \\
\hline & Mpigi & 20 & 16.1 \\
\hline & Masaka & 58 & 46.7 \\
\hline & Bukomansimbi & 25 & 20.1 \\
\hline & Total & 124 & 100 \\
\hline & Age of the Respondents & & \\
\hline & $18-27$ & 38 & 30.1 \\
\hline \multirow[t]{5}{*}{ Valid } & $28-37$ & 47 & 38.2 \\
\hline & $38-47$ & 23 & 18.7 \\
\hline & 48 and above & 16 & 13.0 \\
\hline & Total & 124 & 100 \\
\hline & Level of Education & & \\
\hline \multirow[t]{6}{*}{ Valid } & Certificate & 43 & 34.7 \\
\hline & Diploma & 19 & 15.3 \\
\hline & Degree & 46 & 37.1 \\
\hline & Postgraduate & 16 & 12.9 \\
\hline & Total & 124 & 100.0 \\
\hline & Occupation of Respondents & & \\
\hline \multirow[t]{6}{*}{ Valid } & Farmer & 19 & 15.3 \\
\hline & Trader & 47 & 37.9 \\
\hline & Civil servant & 26 & 21.0 \\
\hline & Chairman & 21 & 16.9 \\
\hline & Councilors & 11 & 8.9 \\
\hline & Total & 124 & 100.0 \\
\hline
\end{tabular}


Table 2 indicates the categorization of participants depending on their gender. The outcome indicates that the majority of participants were males (71\%). These outcomes/results are a representation of employment patterns in Uganda where males dominate the formal sector (Uganda Business Register 2001/2002). Table 2 reflects categorization of respondents according to the type of Stakeholder Category. Results show that majority of the participants were beneficiaries or community members about $63.7 \%$, trailed by the project management at about $20.9 \%$ and others are the least at $15.3 \%$. Table 2 shows the categorization of respondents according to the Place of residence. Results indicated that most of the participants have been in Masaka with 46.7\% and Bukomansimbi. 20.1\%.The results further indicate that the respondents from Mpigi comprised of $16.1 \%$ while those from Kalungu were $8.8 \%$ and lastly Wakiso with $8.0 \%$. Table 2 indicates the categorization of participants according to their age. Results show that most of the participants were between 28 and 37 years of age, about $38.2 \%$, followed by the age range $18-27$ years in the range of $30.1 \%$. Results also indicate that respondents above 48 years of age are the least, about $13 \%$.

The results reflect the existence of an active labor force aged between 20 and 50 years. Table 2 reflects categorization of respondents according to the level of education. Results show that most of the participants held a bachelor's degree about 37\%, trailed by certificate holders at about 35\%. Diploma and Postgraduate certificate holders are the least at $15 \%$ and about $13 \%$ respectively. These results reflect the effect of Government education policy which has liberalized tertiary education. This has led to an increase in private universities, private sponsorship and enrolment at Universities. Table 2 shows the categorization of respondents according to their occupation. Outcomes/Results showed that majority of the participants were been traders within the areas of study with $37.9 \%$. The results further indicate that the respondents that civil servants comprised of $21 \%$ while the chairmen in these areas comprised of $16.9 \%$ and farmers comprising of $15.3 \%$ while the area councilors constituted of $8.9 \%$. Results conform to the element of having different project beneficiaries within different areas of study.

Correlation/Relationship Analysis: Spearman's rank correlation analysis was employed to establish the connection between the study variables. Cultural attributes, multinational project management processes and project technologies were the independent variables while project performance was the dependent variable.

Table 3: Correlation Analysis

\begin{tabular}{lllll}
\hline & $\mathbf{1}$ & $\mathbf{2}$ & $\mathbf{3}$ & $\mathbf{4}$ \\
\hline Culture attributes (1) & 1 & & & \\
$\begin{array}{l}\text { Multinational project } \\
\text { processes (2) }\end{array}$ & management & .125 & 1 & \\
Project technologies (3) & $.577^{* *}$ & .126 & 1 & \\
Project Performance (4) & $.535^{* *}$ & $.758^{* *}$ & $.656^{* *}$ & 1 \\
\hline
\end{tabular}

**. Correlation is significant at the 0.01 level (2-tailed).

Relationship between People's Cultural Attributes and Project Performance: The analysis from Table 3 reveals that there was observed to be a noteworthy positive correlation between people's cultural attributes and the performance of projects $\left(\mathrm{r}=.535^{* *} \mathrm{p} \leq 0.01\right)$. Which implies that if project implementers put in mind the people's culture or way of doing things then clients are likely to become satisfied with the services offered hence leading to positive project performance. These findings are in agreement with the views given by interviewees who explained that the satisfaction they derive from certain implemented projects in their district is primarily driven by their perception of how their culture attributes are considered.

Relationship between Multinational Project Management Processes and Project Performance: Findings in Table 3 further show a positive significant relationship between multinational project management processes and project performance $\left(\mathrm{r}=.758^{* *} \mathrm{p} \leq 0.01\right)$. Indicating that once the project implementers have put in place satisfactory or wanted multinational project management processes, the 
more they perceive the performance of the project positively. The results are in line with the views given by the respondents interviewed who explained that donors put high pressure on project implementers to provide and deliver high-quality services. They further explained that donors develop needs and expectations which directly push project managers to improve on the performance of the projects.

Relationship between Project Technologies and Project Performance: Findings in Table 3 further show a positive significant relation between project technologies and project performance $\left(\mathrm{r}=.656^{* *} \mathrm{p} \leq 0.01\right)$. Meaning that the more adaptive project technologies are put in place, the more they perceive the performance of the project positively. The results are in line with the views given by the respondents interviewed who explained that improved technological advancements in project implementation will directly lead to the completion of work in time, therefore, meeting client expectations. They further explained that project implementers need to develop and fulfill the needs and expectations which directly push for the performance of the project.

Regression Analysis: This was adopted to establish how independent variables of people's cultural attributes, Multinational project management processes, project technologies affect project performance of these World Bank projects in Uganda's energy sector. It's especially used to ascertain the mutual effect the independent variables have on the dependent variable. It is shown by the modified R-square.

Table 4: Regression Analysis

\begin{tabular}{|c|c|c|c|c|c|c|c|c|c|}
\hline \multirow[t]{2}{*}{ Model } & \multicolumn{2}{|c|}{$\begin{array}{l}\text { Unstandardized } \\
\text { coefficients }\end{array}$} & \multirow[t]{2}{*}{$\begin{array}{l}\text { Standardized } \\
\text { coefficients }\end{array}$} & \multirow[t]{2}{*}{$\mathbf{t}$} & \multirow[t]{2}{*}{ Sig. } & \multirow[t]{2}{*}{$\begin{array}{l}\text { R- } \\
\text { square }\end{array}$} & \multirow[t]{2}{*}{$\begin{array}{l}\text { Adjusted } \\
\text { R- } \\
\text { square } \\
\end{array}$} & \multirow[t]{2}{*}{$\mathbf{F}$} & \multirow[t]{2}{*}{$\mathbf{p}$} \\
\hline & B & $\begin{array}{l}\text { Std. } \\
\text { error }\end{array}$ & & & & & & & \\
\hline (Constant) & 1.047 & .490 & & 2.136 & 0.35 & .442 & 424 & 23.805 & .000 \\
\hline $\begin{array}{l}\text { People's } \\
\text { cultural } \\
\text { attributes }\end{array}$ & .321 & .104 & .299 & 3.097 & .003 & & & & \\
\hline $\begin{array}{l}\text { Multinational } \\
\text { project } \\
\text { management } \\
\text { processes }\end{array}$ & $4.024 \mathrm{E}-03$ & .091 & .004 & .044 & .965 & & & & \\
\hline $\begin{array}{l}\text { Project } \\
\text { technologies }\end{array}$ & .396 & .084 & .457 & 4.717 & .000 & & & & \\
\hline
\end{tabular}

Dependent Variable: Project Performance

The results in table 4 indicated that without people cultural attribute, Multinational project management processes and project technologies, project performance are at 1.047. The table further shows that any variation in people's cultural attributes, Multinational project management processes and project technologies lead to a $0.299,0.004$ and 0.457 change in project performance respectively. The results in Table 4.8 also indicated that $42.4 \%$ of the discrepancy in project performance by World Bank projects in Uganda's energy sector implementers is attributed to people's cultural attributes, Multinational project management processes and project technologies (Adjusted R square $=.424$ ). However, it is only project technologies and People's cultural attributes that are statistically significant predictors of project performance amongst project beneficiaries, $(p=.000)$.

Discussion of Results: The discussions of results were based on the objectives and the outcomes/findings of the research as below; 
The Relationship between People's Cultural Attributes and Project Performance: The outcomes of the research indicate a greater substantial relationship between people's cultural attributes and project performance. This is an indication that projects managers who put in place values that put in mind people's cultural attributes such as have a fair chance of having improved project performance. Similar studies by Zeng et al. (2013) and Obikunle (2002) to a greater extent, culture orientations determine how individuals and companies respond to communications and how they generally go about their daily operations. It further indicated that conflicts at workplaces are in most cases a result of misconceptions due to cultural diversities. Therefore, owing to the consequences of these diversities, it is paramount that management gives them great attention and addresses the concerns among teams. Similar studies by Lima and Patah (2016), reveals that short of that is a recipe for project performance being undermined by unwarranted rifts driven by underlying cross-cultural differences. Hofstede (1997) stressed that national culture has a strong impact on employee and further elaborated that evidence indicates that cultural values are adopted earlier in life and considered fundamental in life, they gradually change over the generations.

They have a strong impact on people that they are reflected on cross-culturally implemented projected. Similarly, the project manager's leadership approach and his/her capabilities is a very significant contributor to the success of the project, however, the various types of the project may require different sets of skills (Turner \& Muller, 2005). They further assert that different cultures attached different importance to successes of the various projects, implying that analysis of project success varies across the different cultures because the choice to determine the success of the project is from the value assigned by the different societies. However, culture may hurt project performance or success where management of leadership does not have adequate knowledge of the diverse cultures of the team members they lead or that of the beneficiaries. Similar studies by Lima and Patah (2016), assert that not having sufficient knowledge on the different team members cultures most probably cause misinterpretations, drops in self-esteem, conflicts at work and religious clashes for teams that are geographically apart.

The Relationship between Multinational Project Management Processes and Project Performance: The outcomes of the research reveal a modest important positive relationship between multinational project management processes and project performance. This is an indication that once the project implementers have put in place satisfactory or wanted multinational project management processes, the more they perceive the performance of the project positively. Similar studies by Ahimbisibwe \& Nangoli (2012), confirm that capabilities and the potential of the public sector are very important to the growth of the country's economy. Therefore there is a need to invest in project management skilling in member agencies that participate in the development of the country's investments. However, observed various factors that contribute to the difficulty in the performance of global projects i.e. Currency fluctuations, surges in global prices of raw materials, diversity in cultures, political pressures, harsh environments and greater public visibility of these projects rather than multinational project management processes.

The Relationship between Project Technologies and Project Performance: The study results indicate a strong important constructive correlation between Project Technologies and Project Performance. This implies that the more adaptive project technologies are put in place, the more they perceive the performance of the project positively. Similar studies by Crawford \& Cox (2007), who explained that improved technological in project implementation, will directly lead to the completion of work in time, therefore, meeting client expectations. Schmid and Adams (2008), confirms that project performance relies on effectiveness and efficiency in the execution of the project activities for the success to be realized. These findings are supported by the similar works of Marmgren and Ragnarsson (2014), who assert that although the characteristics of a project are very important to realize good management, adopting advanced technological knowledge also stand better chances to deliver more efficiently and effectively and therefore perform better. Similar studies are supported by Schmid and Adams (2008), who confirms that over the previous two decades, big organizations have engaged in the development of more advanced designs and models of products through high tech processes and control systems.

Their observation is that through only increasing the efficiency of complicated projects, positive results have not been realized. Therefore, technology transformation match advances in other factors of production like 
human capital to reduce the risk of the advancements in processes and description capacities being laid back by un-matching capabilities from other factors of production. However, According to Kerrin and Oliver (2002), advancement in technological knowledge presumes relevance for contexts of project management practice in today's technology-enabled work environment, where this knowledge is mainly used for support, relaying information and engagement of management toolsets. Studies further revealed that it's lately getting common to apply electronic medium even among project members that share locations. Putting aside the relevance of technology, existing research has shown that it is not easy to relate it the use of technological advances with business (Kerrin and Oliver, 2002), performance and the lack of such relationships can be induced to project performance as well. However, besides technology, other major factors can play a major role in facilitating project managers to effectively manage projects without technology being apart.

\section{Conclusions, Recommendations and Implications}

Conclusions: People cultures and project technologies were among the best constructs noted to be significant predictors of project performance in the Power Sector Development Operation Project and Electricity Sector Development projects implemented in Uganda. These results were a confirmation of the Person correlation coefficient results. This shows that project managers that implement favorable project technologies mechanisms and embedment of people's culture are more likely to access projects than their counterparts that neglect the practices mentioned above. In other words, access to public projects among governmental institutions is largely defendant on people's culture attributes and project technologies. Good project performance may also be attributed to good multinational project management. Finally, the predictor variables in this study account for $42.4 \%$ of the performance of projects. This covers only the people's culture and project technologies while multinational project management was confirmed non-significant predictors of project performance. The remaining percentage may be associated with other factors outside this study. This is because access to public projects by governmental parastatals is affected by factors which differ from one project to another. Thus, it is important to consider a variety of factors as they apply to each project than to generalize the predictors of project performance.

Recommendations: To improve project performance based on people's cultures and project technologies in the Power Sector Development Operation Project and Electricity Sector Development projects implemented in Uganda, all Project managers and/or other practitioners in line of duty for implementing multinational projects from donor funding need to ensure that there is a commitment from all project staff. This will ensure that they always work towards the achievement of the project objectives. In principle, this should be cultivated through creating a sense of ownership of the project staff which in a way creates a favorable and somewhat fulfilling atmosphere that motivates them to not only continue with the teamwork but also keep the focus towards the project goals.

This practice creates a culture of positivity in the team that will thus make it easy to welcome the project targets and also adopt the guidelines of the stakeholders e.g. among others. This kind of spirit makes it easy to overcome the various project challenges associated with the underlined project implementation framework which improves the performance of the project and hence success. Also, the involvement of other key stakeholders like the project beneficiaries or the Project Affected Persons (PAPs) is a very important aspect that this research has proved to be vital in the implementation of these international projects. This ensures proper undressing of the cultural orientations of these persons, appreciation of their social-economic activities and how the project activities can either enhance or improve them.

Which ensures a sustainable positive impact and development in these communities? Their involvement also breeds a sense of ownership from their perspective, he is important because, it is easy to appreciate the technologies involved, and also security of the project materials especially since most are infrastructural projects that are mostly faced with implementation delays associated with vandalism and theft of materials. Proper understanding and involvement of local beneficiaries have far enriching benefits to project performance and success, both from the acceptance of project objectives, implementation processes and sustainably, this research found it so paramount for project managers to consider this aspect as key and also address it to their Top managers to appreciate and support it through timely release of project disbursements 
directed towards these activities especially for citizenship projects. Project managers must seriously consider undertaking training to adopt the various projects management technologies and processes if they are to achieve the desired project objectives under different circumstances. Insightful planning and considerations must be considered when developing multinational project management processes and plans as it is a paramount predictor of project performance and success since it's through initial planning that project managers with the entire team develop the blueprint that spells out the entire project life cycle.

The various tools/techniques usually employed in these processes should be well comprehended and engaged when required to assist in these processes. Effective periodic performance appraisal and reporting, as well as administrative closure, should be conducted on a routine basis to track progress and the eventual project success. The function of categorizing projects while using methodical procedures has to be should be encouraged on every multinational project. It shouldn't be left upon the beneficiaries of the project. It ought to be arranged in a unified function where both donor partners and beneficiaries are inclusively engaged. The benefit of this is to ensure that commendable ideas are developed and integrated into the project concept, this in a way aids the project to have a significant impact on the project deliverables. The quantification of completed works at the different project phases should be conducted by the contract/project managers. Since it will always encourage suppliers or contractors to expedite practice intensify their site deployment and coordination with material suppliers to increase the progress of works. Coordination between the key stakeholder's premises, for example, the Donor agency/ the Financier, the implementing agency, any local Government offices that link with the beneficiary communities should be encouraged in order enable timely sharing of information and facilitate monitoring of the project activities. This, in turn, will mitigate slippages from the schedules and hence leading to project success.

Implications and Contribution to knowledge: Since Uganda's economy is on the onset of developing, with various infrastructural projects being implemented and other packaged across all public sectors. Several new techniques and methodologies of managing these projects are coming on board, this is all in the bid to mitigate the risks of losing these project investments and also revenue for Government through bad deals. There is a need to comprehend these practices and appreciate their relevance and impact on the success of the projects. Through these additional skills, management professionals in project, project beneficiaries and Policy analysts increasingly apprise themselves on both the positive and negative impacts that result from engaging in these practices. Therefore it would facilitate discussions of informing management on a more robust way of managing and enabling effective controls, monitoring to realize project success. An inclusive study of all the fundamental factors that influence project time, cost and quality are very important in the procedures of practicing project management.

Begin aware of the relationship between people's cultural attributes, multinational project management processes, project technologies and project performance in the various development sectors in the country would be of great importance to the evaluation. Specifically, almost all projects about the country's energy sector are often faced with challenges of delayed implementations that result in continued extensions. This is has failed to complete most of these project in the required timeframes and thus resulting in unnecessary expenditures on Government. This indeed indicates the much-desired need to effectively take into account and monitor the factors of project performance while also creating more awareness amongst stakeholders indicating to them the losses incurred in failure to meet objectives within required periods. The research is thus expected to add or contribute to the existing research stream by bringing out and examining the relationship between project performances (the independent variables) to researchers. However, the study has a few limitations.

Finances were one of the limiting factors since the researcher had to travel to many districts of Uganda in search of data; however, the Ministry availed me with some financial support that helped me so much. Some respondents were hesitant to answer the questions for fear of reappraisal, however, the letter of an introduction made the respondents confident that the information they were giving me was purely academic. The limitation of distributing and collecting the data within 3 months as expected by the University was another challenge; however, with the help of two data collectors, the questionnaires were returned at the time when I needed those most. Accessibility to the many places was difficult due to the poor road networks 
and the rainy season which affected data collection. The Researcher ended up visiting a few places than those

that he would have visited due to the interference of rain.

\section{References}

Ahimbisibwe, A. \& Nangoli, S. (2010). Project Communication, Individual Commitment, Social Networks, and Perceived Project Performance. Journal of African Business, 13(2), 101-114

Akeke, N. I., Akeke, A. R. \& Awolusi, O. D. (2015). The Effect of job satisfaction on organizational commitment among non-academic staff of tertiary institutions in Ekiti state, Nigeria, International Journal of Interdisciplinary Research Method, 2(1), 25-39.

Awolusi, O. D. (2019). Human Capital Development and Economic Growth in BRICS Countries: Controlling for Country Differences, Journal of Economics and Behavioral Studies, 11(4), 1-17.

Badiru, B. A. (2008). Triple C Model of Project Management: Communication, Cooperation and Coordination, Taylor and Francis Group.

Barney, J. \& Clark, D. (2006). Resource-based theory: creating and sustaining competitive advantage, oxford University Press, Oxford, UK.

Battistuzzo, F. J. \& Piscopo, M. (2015). Global projects: a Bibliometric Study of International Business Journals. Internext: Revista Eletronica de Negocios Internacionais da ESPM, 10(2), 31-45.

Bojesson, C. (2015). Improving project performance in product development, Mälardalen University Press Licentiate Theses No. 192.

Campbell, J. L. (2004). Institutional Change and Globalization. Princeton University Press.

Chan, A. \& Chan, A. (2004). Key performance indicators for measuring construction success. Benchmarking, 11(2), 203-221.

Cheng, C. P. J., Lwa, H. K., Bjornsson, H., Jones, A., Sriram, R. (2010). A Service-Oriented Framework for Construction Supply Chain Integration, Automation in Construction, 19(2), 245-260.

Cheetham, G., \& Chivers, G. E. (2005). Professions, Competence and Informal Learning. Edward Elgar Publishing.

Ching, G. V., Hoffman, J., Cao, Q. \& Schniederjans, J. M. (2014). The effects of organizational culture and environmental pressures on IT project performance: a moderation perspective, International Journal of Project Management, 32(7), 1170-1181.

Choa, K., Hong, T., Hyun, C. (2009). Effect of project characteristics on project performance in construction projects based on structural equation model. Expert Systems with Applications, 36(7), 10461-10470.

Clarkson, J. \& Eckert, C. (2010). Design Process Improvement. A review of current practice. Springer Science \& Business Media.

Crawford, M. K. \& Cox, F. J. (2007). Designing performance measurement systems for just-in-time operations, International Journal of Production Research, 28(11) 2025-2036.

Daniel, S, J. \& Reitsperger, W. D. (1991). Linking quality strategy with management control systems: empirical evidence from Japanese industry. Accounting, Organizations and Society, 16(7) 601-18.

Deming, E. W. (1982). Quality, Productivity and Competitive Position. Massachusetts Institute of Technology, Center for Advanced Engineering Study.

Easterby-Smith, M., Thorpe, R. \& Jackson, P. (2008). Management Research. Sage series in management research.

European Commission (2007). Annual Report

Frese, R. \& Sauter, V. (2003). Project success and failure: what is a success, what is a failure, and how can you improve your odds for success? Available at http://www.umsl.edu/ sauterv/analysis/6840_f03_papers/frese/

Ghauri, P. \& Gronhaug, K. (2010). Research Method in Business Studies. 4th Edition, Pearson, London.

Gleitsmann, B. (2005). The importance of community involvement in the planning and design phases of rural water supply development projects in the Koro region of Mali, West Africa.

Hallowell, M. \& Toole, M. (2009). Contemporary Design-Bid-Build Model, Journal of Construction Engineering and Management, 135(6), 540-550.

Hansen, S. C., Otley, D. \& Van der Stede, A. W. (2003). Practice Developments in Budgeting: An Overview and Research Perspective. Journal of management accounting research, 15, 95-116. 
Harrell, P. S. \& Bond, A. M. (2006). Listening to diversity stories: principles for practice in community research and action. American Journal of Community Psychology, 37(3-4), 365-376.

Helfat, C., Finkelstein, S., Mitchell, W., Peteraf, M., Singh, H., Teece, D. \& Winter, S. (2007). Dynamic capabilities: understanding strategic change in organizations. Blackwell Publishing, Malden, UK.

Hofstede, H. G. (1997). Cultures and organizations: Software of the mind, McGraw-hill.

Hofstede, G. (2011). Dimensionalizing Cultures: The Hofstede Model in Context. Online Readings in Psychology and Culture, 2(1).

Hyvari, I. (2006). Project management effectiveness in project-oriented business organizations. International Journal of Project Management, 24(3), 216-225

ITAP International. (2014).

Jetu, F. T., Riedl, R. \& Roithmayr, F. (2010). Cultural patterns influencing project team behavior in SubSaharan Africa: a case study in Ethiopia. Project Management Journal, 42(5), 57-77.

Jugdev, K. \& Müller, R. (2005). A retrospective looks at our evolving understanding of project success. Project Management Journal, 36, 19-31.

Kerrin, M., \& Oliver, N. (2002). Collective and individual improvement activities: The role of reward systems. Personnel Review 31(3), 320-337.

Khang, D. B. \& Moe, L. (2016). Success Criteria and Factors for International Development Projects: A LifeCycle-Based Framework. Project Management Journal, 39(1), 72-84.

Kothari, C. R. (2004). Research Methodology: Methods and Techniques, (Second Edition), New Age International Publishers.

Krejcie, R. V. \& Morgan, D. W. (1970). Determining sample size for research activities. Educ Psychol Meas, 30(3), 607-10.

Lavrakas, P.J. (2008). Encyclopedia of survey research methods. Sage Publications, Inc., Thousand Oaks.

Lima, N. \& Patah, A. L. (2016). Cultural issue and its influence in the management of global project teams. Future Studies Research Journal, 8(1), 90-112.

Lin, Y., Chen, A. S. \& Song, Y. (2012). Does your intelligence help to survive in a foreign jungle? The effects of cultural intelligence and emotional intelligence on cross-cultural adjustment. International Journal of Intercultural Relations, 36(4), 541-552.

Mansfield, N. R., Ugwu, O. O. \& Doran, T. (2015). Causes of delay and cost overruns in Nigerian construction projects. International Journal of Project Management, 12(4), 254-260.

Marmgren, L. \& Ragnarsson, M. (2014). Leading uncertain and complex projects. Lund: Student literature.

Meng, X. (2011). The effect of relationship management on project performance in construction. International Journal of Project Management, 30(2), 188-198.

Meredith, J. R. \& Mantel, J. S. (2000). Project management. A managerial approach $\left(7^{\text {th }}\right.$ Ed). John Wiley \& Sons Inc.

Ministry of Energy and Mineral Development report. (2017).

Neely, A., Mills, J., Platts, K. \& Gregory, M. (1994). Realizing strategy through measurement, International Journal of Operations \& Production Management, 14(3), 140-52.

Nunnally, J. C. (1978). Psychometric theory (2nd ed.). New York: McGraw-Hill.

Obikunle, O. (2002). Dealing with cultural diversity in project management: a dilemma in communication. Proceedings of the PMI Annual Seminar \& Symposium, San Antonio, TX, USA.

O'Donnell, F. J. \& Duffy, A. H. B. (2002). Modeling design development performance, International Journal of Operations \& Production Management, 22(11), 1198-1221.

Ofori, F. D. (2013). Project Management Practices and critical success factors-a developing country perspective. International Journal of Business and Management, 8(21).

Ojanen, V., Piippo, P. \& Tuominen, M. (2002). Applying quality award criteria in R\&D project assessment. International journal of production economics, 80(1), 119-128.

Pires, J. C. S., \& Macedo, K. B. (2006). Cultura organizacional em organizações públicas no Brasil. Revista de Administração Pública - RAP, 40(1), 81-105.

Power Africa Uganda report. (2015).

Project Management Institute - PMI. (2013). A guide to the project management body of knowledge PMbok® guides (5th Ed.). Pennsylvania: PMI.

Russo, R. F. S. M., Ruiz, J. M., \& Cunha, R. P. D. (2005). Liderança e influência nas fases da gestão de projetos. Revista Produção, 15(3), 362-375. 
Schmid, B. \& Adams, J. (2008). Motivation in project management: the project manager's perspective. Project Management Journal, 39(2), 60-71.

Sink, D. S. (1985). Productivity Management-Planning, Measurement and Evaluation, Control and Improvement, Wiley, New York.

Skinner, W. (1969). Manufacturing - the missing link in corporate strategy, Harvard Business Review, MayJune.

Slack, N. (1987). The flexibility of manufacturing systems. International Journal of Operations \& Production Management, 7(4), 35-45.

Steers, R., Nardon, L. \& Sanchez-Runde, C. (2013). Management across Cultures: Developing Global Competencies. Cambridge University Press, 2013 - International business enterprises.

Sumner, M., Bock, D. \& Giamartino, G. (2006). Exploring the linkage between the characteristics of IT project leaders and project success. Information Systems Management, 23(4), 43-49.

Todorović, M. L., Petrović, D. Č., Mihić, M. M., Obradović, V. L., \& Bushuyev, S. D. (2015). Project success analysis framework: A knowledge-based approach in project management. International Journal of Project Management, 33(4), 772-783.

Turner, J. R. (2009). The handbook of project-based management (leading strategic change in organizations). New York, NY: The McGraw-Hill Companies Inc.

Turner, R. \& Muller, R. (2005). The Project Manager's Leadership Style as a Success Factor on Projects: A Literature Review, Project Management Journal, 36(2), 49-61

Wheelwright, C. S. (1984). Manufacturing strategy - defining the missing link, Strategic Management Journal, $5(1), 77-91$.

Wiewiora, A., Trigunarsyah, B., Murphy, G. \& Coffey, V. (2013). Organizational culture and willingness to share knowledge: a competing values perspective in the Australian context, International Journal of Project Management, 31(8), 1163-1174.

worldbank.org. (2018). Projects and operations. [ONLINE].

Wysocki, R. K., Beck, R. \& Crane, B. D. (2000). Effective Project Management, 2nd Edition 2nd Edition, Wiley.

Ying, Z., Christopher, M., Sergey, F., Henk-Jan, H. \& Martijn, van der S. (2015). The Challenges and Enhancing Opportunities of Global Project Management: Evidence from Chinese and Dutch Cross-Cultural Project Management. Working Paper 15-063, Harvard Business School.

Zein, O. (2012). Cultural complexities in multinational projects. Proceedings of the PMI Global Congress EMEA, Marseille, France.

Zeng, Y., Shenkar, O., Lee, S. \& Song, S. (2013). Cultural differences, MNE learning abilities, and the effect of experience on subsidiary mortality in a dissimilar culture: evidence from Korean mines, Journal of International Business Studies, 44(1), 42-65. 